\title{
IEC/EN standards relating to diagnostic radiology equipment, and testing according to these standards
}

\author{
- REVIEW ARTICLE - \\ ${ }^{1}$ Frederic Joliot-Curie National Research Institute for Radiobiology and Radiohygiene (NRIRR), \\ Budapest, Hungary \\ ${ }^{2}$ IEC \& CENELEC TC62 Hungarian National Committee, Budapest, Hungary \\ e-mail:porubszky@osski.hu
}

The paper gives an outlook of history, present and future of international (IEC) and European (EN) standards relating to diagnostic radiology equipment. These standards may be safety, quality assurance or performance standards; all of them include testing methods. Elaboration and publication of a new series of safety standards is in progress.

Acceptance and conformance testing activity of the accredited Radiohygiene Department Laboratory of NRIRR according to these standards is reported.

Key words: diagnostic radiology; standardization; safety; quality assurance; International Electrotechnical Commission.

\section{Introduction}

Technical Committee 62 (TC62) of International Electrotechnical Commission (IEC) elaborates safety, quality assurance or performance standards relating to - among others - diagnostic radiology equipment. All these standards contain definitions of terms and testing methods. 
First part of the paper gives a review about foundation, history and working method of IEC as well as system of radiology-related standards and actual changing of this system. Hungarian participation is also mentioned.

In the second part use of the standards is explained. Moreover, a report of one of the users of these standards is included.

In conclusions, future prospects of the standards and their practical use are analysed.

\section{International and European standardization concerning diagnostic radiology equipment}

\section{Foundation of the International Electrotechnical Commission (IEC)}

On September 15, 1904, delegates to the International Electrical Congress, being held in St. Louis, USA, adopted a report that included the following words: “...steps should be taken to secure the co-operation of the technical societies of the world, by appointment of a representative Commission to consider the question of the standardization of the nomenclature and ratings of electrical apparatus and machinery."

As a result, IEC was officially founded in June 1906, in London, England, where its Central Office was set up. Hungary is one of the founding members. By 1914 the IEC had formed four technical committees. By 1923 the number of technical committees had increased to 10, by 1980 to 80 . In 1948 the IEC Central Office moved from London to Geneva. Income of the IEC Central Office, which has about 50 employees, is only from purchasing standards and membership fees of the member states. At present IEC has about 110 technical committees (TCs).

\section{Technical Committee 62, Medical Electrical Equipment (TC 62) of IEC}

In 1969 IEC created Technical Committee 62 for medical X-ray equipment, which committee later was enlarged to incorporate all medical electrical equipment. Again Hungary was amongst the first members to take part in this committee. The first meeting of TC 62 took place in Baden-Baden (Germany).

At present the TC 62 has four Sub-Committees (SCs):

- SC 62A Common Aspects of Electrical Equipment used in Medical Practice,

- SC 62B Diagnostic Imaging Equipment (formerly X-Ray Equipment), 
- SC 62C Equipment for Radiotherapy, Nuclear Medicine and Radiation Dosimetry,

- SC 62D Electromedical Equipment.

TC 62 and its Sub-Committees have meetings usually every 18 months.

\section{Comité Européen de Normalisation Electrotechnique (CENELEC)}

CENELEC European electrotechnical organization was founded in 1973 and its Central Office is located in Brussels. Hungary became affiliated member of CENELEC in 1991 and became regular member in 2002 , July $1^{\text {st }}$.

CENELEC TC 62 deals with medical electrical equipment in the European Union. Hungary is also an active member in this Technical Committee through the Hungarian Standards Institution. CENELEC TC 62 usually takes over the IEC TC 62 standards. FDIS (Final Draft International Standards) issued for voting by IEC TC 62 are issued for parallel voting: for IEC TC 62 P members and for CENELEC TC 62 members. CENELEC TC 62 has meetings in every 12 months.

\section{Participation of Hungary in the work of IEC TC 62 and CENELEC TC 62}

Hungary takes part in IEC TC 62 through the Hungarian Standards Institution both in TC62 and SC meetings and also is very active in SC 62A and SC 62B. In both committees Hungary is $\mathrm{P}$ (participating) member, with voting obligation. Hungarian experts take part also in Working Group (WG) or Maintenance Team (MT) meetings. In SC 62C and $\mathrm{SC} 62 \mathrm{D}$ Hungary is $\mathrm{O}$ (observer) member. Hungarian experts take part also in CENELEC TC 62 meetings.

The Hungarian Standards Institution established its Technical Committee 843 to deal with IEC TC 62 and CENELEC TC 62 matters in 1995. TC 843 (as the Hungarian National Committee to IEC TC 62, SC 62A, SC 62B and to CENELEC TC 62) has meetings regularly especially when IEC TC 62 / CENELEC TC 62 Standards are translated to Hungarian language. These standards have MSZ-EN (Hungarian Standard - European Standard) heading.

According to the European Union and Hungarian regulations all medical equipment shall meet the European MDD (Medical Devices Directive 93/42 EEC) [1] requirements. 


\section{Working method of IEC}

Members of IEC are the National Committees (NCs) of countries. In elaboration of standards each country may participate - if it is intended - by delegation of experts into the working groups, nominated to the Central Office. Bodies participating in National Committees generally are: manufacturers, representatives of users, test houses, professional societies, governmental bodies, commercial agencies etc.

If - in national level - there is a demand for elaboration of a new standard or revision of an existing one, the NC may propose it to the IEC. Then the corresponding Technical Committee asks member NCs for voting, and in case of acceptance of the topic a new working group (WG) or maintenance team (MT) will be founded, with experts delegated by member NCs. Its necessary condition is delegation of experts at least from five member states. Drafts of the planned standard are circulated among member NCs for commenting and for voting several times in different stages. Based on the comments the WG revises the draft and it is circulated again. At the end if the FDIS (final draft international standard) is accepted by member $\mathrm{NCs}$ it will become international standard. This procedure lasts at least 14 months but often even 4 years. International standards express, as nearly as possible, an international consensus.

\section{Standards for medical electrical equipment}

They belong into 3 main groups:

1. Safety (and essential performance) standards: requirements and test methods of compliance,

2. Quality assurance standards: test methods for equipment in operation,

3. Performance standards: definitions and measuring methods of characteristics of the equipment,

Furthermore, there is also one standard only for Electromagnetic compatibility (EMC). It is important to note that for medical procedures themselves there are no standards.

\section{Safety standard family of medical electrical equipment}

- IEC 60601-1 Medical Electrical Equipment - Part 1: General requirements for basic safety and essential performance: the so-called general standard. Its $3^{\text {rd }}$ edition was accepted in December 2005 as IEC standard (and in September 2006 by CENELEC as Euronorm [2], and in March 2007 as Hungarian standard). 
Table 1. Present system of IEC standards relating to diagnostic radiology

\begin{tabular}{||l||c|c|c||}
\hline \hline \multicolumn{1}{||c||}{ Performance } & $\begin{array}{c}\text { Radiography } \\
\text { / radioscopy }\end{array}$ & $\begin{array}{c}\text { Interventional } \\
\text { radiology / DSA }\end{array}$ & Mammography \\
\hline \hline \multirow{3}{*}{ X-ray tube assemblies } & 60336 & 60336 & 60336 \\
& 60613 & 60613 & 60613 \\
& 60522 & 60522 & 60522 \\
High voltage cables & 60806 & 60806 & 60806 \\
\hline \multirow{2}{*}{ Quantum efficiency } & 60526 & 60526 & 60526 \\
\hline
\end{tabular}

\begin{tabular}{||l||c|c|c||}
\hline \multicolumn{1}{|c||}{ Safety } & $\begin{array}{c}\text { Radiography } \\
\text { / radioscopy }\end{array}$ & $\begin{array}{c}\text { Interventional } \\
\text { radiology / DSA }\end{array}$ & Mammography \\
\hline \hline General standard & $60601-1$ & $60601-1$ & $60601-1$ \\
\hline Radiation protection & $60601-1-3$ & $60601-1-3$ & $60601-1-3$ \\
\hline X-ray generator & $60601-2-7$ & $60601-2-7$ & \\
\hline Examination devices & $60601-2-32$ & $60601-2-32$ & $60601-2-32$ \\
\hline X-ray tube assembly & $60601-2-28$ & $60601-2-28$ & $60601-2-28$ \\
\hline Particular standards & & $60601-2-43$ & $60601-2-45$ \\
\hline \hline
\end{tabular}

\begin{tabular}{||l||c|c|c||}
\hline \hline Quality assurance & $\begin{array}{c}\text { Radiography } \\
\text { / radioscopy }\end{array}$ & $\begin{array}{c}\text { Interventional } \\
\text { radiology / DSA }\end{array}$ & Mammography \\
\hline \hline Acceptance tests & $61223-3-1$ & $61223-3-3$ & $61223-3-2$ \\
\hline Constancy tests & $61223-3-4$ & $61223-2-9$ & $61223-2-10$ \\
\hline \hline
\end{tabular}


- IEC 60601-1-X: so-called collateral standards. They apply to groups of products, e.g. for X-ray equipment. They are also general but may be more easily revised than the general standard.

- IEC 60601-2-X: so-called particular standards. They apply to a given product type, e.g. a given modality of imaging equipment. They have priority over the general and the collateral standards.

Risk factors dealt with in safety standards: electrical safety, mechanical safety, radiation protection, EMC, risk management, equipment systems, environmental protection, safety systems, biological compatibility, usability, software safety, data safety etc.

The present system of IEC standards relating to diagnostic radiology is shown on Table 1.

\section{Steering group X-ray - changing in the system of safety standards of diagnostic radiology equipment}

In 2005 a special advisory group of Chairman of SC62B was convened for laying down basic principles for revision of X-ray related collateral and particular standards in relation to the transition from $2^{\text {nd }}$ to $3^{\text {rd }}$ edition of the general standard. (Safety standard family connected to the $3^{\text {rd }}$ edition of the general standard is a system-based approach, instead of the earlier component-based one.) According to its decisions:

- The $2^{\text {nd }}$ edition of IEC 60601-1-3 (radiation protection) collateral standard may contain only general requirements valid for all X-ray modalities, all further requirements are to be transferred into the particular standards;

- From modality specific requirements of $1^{\text {st }}$ edition of IEC 60601-1-3 and from IEC 60601-2-7 (X-ray generators) a new particular standard is to be elaborated for conventional (projection) radiography and simple radioscopy (will be IEC 60601-2-54);

- Also creating a new particular standard for dental X-ray equipment is encouraged;

- Series 61223-2 (constancy tests) will be withdrawn (probably except CT) as they were not applied in the practice;

- Several standards will be withdrawn, as their requirements are included in the general standard or in new particular standards. 
Table 2. Future system of IEC standards relating to diagnostic radiology

\begin{tabular}{||l||c|c|c||}
\hline \multicolumn{1}{||}{ Performance } & $\begin{array}{c}\text { Radiography } \\
\text { / radioscopy }\end{array}$ & $\begin{array}{c}\text { Interventional } \\
\text { radiology / DSA }\end{array}$ & Mammography \\
\hline \hline & 60336 & 60336 & 60336 \\
X-ray tube assemblies & 60613 & 60613 & 60613 \\
& 60522 & 60522 & 60522 \\
& 60806 & 60806 & 60806 \\
\hline High voltage cables & 60526 & 60526 & 60526 \\
\hline Quantum efficiency & $62220-1$ & & \\
\hline
\end{tabular}

\begin{tabular}{||l|c|c|c||}
\hline \multicolumn{1}{|c|}{ Safety } & $\begin{array}{c}\text { Radiography } \\
\text { / radioscopy }\end{array}$ & $\begin{array}{c}\text { Interventional } \\
\text { radiology / DSA }\end{array}$ & Mammography \\
\hline \hline General standard & $60601-1$ & $60601-1$ & $60601-1$ \\
\hline Radiation protection & $60601-1-3$ & $60601-1-3$ & $60601-1-3$ \\
\hline X-ray tube assembly & $60601-2-28$ & $60601-2-28$ & $60601-2-28$ \\
\hline Particular standards & $60601-2-54$ & $60601-2-43$ & $60601-2-45$ \\
\hline
\end{tabular}

\begin{tabular}{||c|c|c|c||}
\cline { 2 - 4 } \multicolumn{1}{c|}{} & $\begin{array}{c}\text { Radiography } \\
\text { / radioscopy }\end{array}$ & $\begin{array}{c}\text { Interventional } \\
\text { radiology / DSA }\end{array}$ & Mammography \\
\hline \hline Quality assurance & $\begin{array}{l}61223-3-1 \\
61223-3-4\end{array}$ & $61223-3-3$ & $61223-3-2$ \\
\hline
\end{tabular}

After September 2009, use of old particular standards will be prohibited in CENELEC member states if a new particular standard exists. If there will be neither new nor old particular standard to a given modality (e.g. dental X-ray equipment or bone densitometers) after this date, then manufacturers will be obliged to perform a special individual risk management process for their new products.

The future system of IEC standards relating to diagnostic radiology is shown in the Table 2. 


\section{Some interesting details from the radiation protection standard}

The most problematic part of a standard is its scope. After long discussions, scope of the $2^{\text {nd }}$ edition of IEC 60601-1-3 - which has been published in January 2008 - formulated as follows: "This Collateral Standard applies to X-ray equipment and to subassemblies of such equipment, where images of the patient are used for diagnosis, planning or guidance of medical procedures."

With the technical development meaning of concepts of 'radiography' and 'radioscopy' ('fluoroscopy') became old-fashioned: in modern equipment (pulsed) radioscopy and serial radiography differs only in value of X-ray tube current.

Creation of new definitions was very difficult. The accepted new definitions are the following: "Radiography: technique for obtaining, recording and optionally processing, directly or after transfer, information contained in an X-ray pattern at an image reception area intended to be analysed during a time independent from the irradiation time. (...) Radioscopy: technique for obtaining continuously or periodically a sequence of X-ray patterns and presenting them simultaneously and continuously as visible images, intended to provide a real-time guidance to an ongoing action." (The latter includes gastro-intestinal examinations with spotfilm device, interventional radiology, $\mathrm{X}$-ray guided lithotripsy, surgical-traumatological fluoroscopy, stereotaxy, and radiation therapy simulation.)

Second edition of IEC 60601-1-3 contains numerical requirements only for radiation quality (half value layers) and leakage radiation, all other requirements are moved into the particular standards. The new IEC 60601-2-54 will be published in 2009.

\section{New editions of other standards}

All safety and performance standards are planned to be revised. New edition of all safety standards, harmonized to the new IEC 60601-1 general standard, probably will be published in 2009 .

As to the performance standards, the fourth edition of IEC 60336 (focal spots) has been published recently. At least IEC 60613 (electrical and loading characteristics of X-ray tube assemblies) will be published together with IEC 60601-2-28 (safety of X-ray tube assemblies). Maintenance Team MT32 will revise the remaining X-ray tube assembly performance standards later.

Standards of quality assurance series have been issued between 1996 and 1999, except standard for CT, which was issued in 2004. IEC standard for mammography 
equipment has a recent second edition, which is, however, not harmonized till now by the EU. The older standards are not applicable to the newest equipment so their revision would be needed.

\section{Application of the standards}

\section{Application of safety standards}

In member states of the EU products can be sold only if they are CE-marked. For medical devices, general requirements, contained in Annex I. of directive 93/42 EEC must be fulfilled. Compliance to the so-called harmonized (safety) standards, if declared, must be considered as compliance to the respective general requirement. Although application of standards is 'not compulsory' (i.e. manufacturer in principle may find some other possibility to prove compliance to the respective general requirement - the reason of this assignment is not to hinder the technical development by given standards), the practice is that every manufacturer applies the standards. Almost all manufacturers choose the so-called 'total quality system' according to Annex II of the mentioned directive. In this case testing according to the standards is obligation of the manufacturer itself. The procedure is audited by one of the so-called notified bodies (by EU for medical devices). Notified bodies have also the right to repeat the testing but in the practice it is not usual. According to the directive - in principle - there is also another possible certification path where a 'production quality system' is combined with a so-called type testing. Type testing is performed by a notified body or by - as its subcontractor - a testing laboratory accredited to the needed (part of) type testing.

In other countries (outside EU) generally the co-called IEC EECB certification is the necessary condition of the introduction of a product to the market. This certification contains type testing according to the applicable IEC safety standards, to be performed by a notified body (by IEC) or its accredited subcontractor testing laboratory.

In the USA, FDA (Food and Drug Administration) and in Canada, CSA (Canadian Standards Association) also require IEC EECB certification containing testing protocols according to the applicable IEC safety standards (besides, they have some further own special requirements). 


\section{Application of quality assurance standards}

These can be divided into 'acceptance testing' and 'constancy testing' standards. In the literature and in the international nomenclature concept of 'status testing' is also used for complex routine testing but from practical point of view it contains the same measurements as acceptance testing.

'Acceptance testing' standards (IEC/EN 61223-3 series) are used in some countries, including Hungary, for acceptance (and status) testing of equipment. Most countries, however, even inside the EU, have own special requirements for acceptance testing.

'Constancy testing' standards may be good guidance but - according to the authors' information - they are not used directly in the practice and regulation anywhere.

\section{Application of performance standards}

Performance standards do not contain requirements but definitions and measuring methods so they are used as references during application of both families of other standards.

\section{Testing experiences in Hungary}

\section{Regulation of equipment quality control}

In the European Union (EU), Directive 97/43/EURATOM about radiation protection of patients [2] requires - among others - the good practice of (physical-technical) quality assurance. In Hungary, Decree No. 31/2001. (X.3.) of the Minister of Health harmonizes all of its requirements. Acceptance testing of new diagnostic $\mathrm{X}$-ray equipment is assigned to NRIRR. Further full performance testing (status testing) is required yearly and after major servicing, it is task of accredited independent testing organizations. Simple daily checks (the so-called constancy testing) are the responsibility of users (licensees) themselves. QA programmes are under the surveillance of the radiation health authority (radiation health centres of State Public Health and Medical Officer Service).

\section{Benefits and practice of acceptance testing in Hungary}

According to generally accepted definitions, the main aim of acceptance testing is checking the compliance of the equipment with the contract and/or manufacturer's 
specifications (and local regulations, if applicable). It is the first benefit of the user. In the - very unlikely but in principle possible - case of non-compliance the user can successfully complain using the test report. Testing activity of NRIRR is independent from manufacturers, it is run within the frame of an accredited testing laboratory, using calibrated measuring instruments, performed by highly qualified personnel and based on valid international standards (which are identical with European and also with Hungarian standards). The other benefit for the user is the measuring of the so-called base levels for further QA, i.e. initializing of a QA programme assuring long, safe and optimum performance of equipment.

Acceptance (and also status) testing is based on EN/IEC 61223-3 standard series. The needed universal X-ray parameter measuring devices and other test devices were bought in NRIRR with the financial support of the EU, before full membership of Hungary. Acceptance testing has been continuous since May 2002. During the first six years about 210 acceptance tests were performed. This number includes radiography, tomography and fluoroscopy equipment, mobile radiography equipment, surgical image intensifiers, digital subtraction angiography (DSA) and interventional radiology equipment, mammography equipment, dental panoramic and cephalometric equipment, and - started in 2006 - CT equipment, too. Almost in every third case some need for servicing or adjustment was detected. The most frequent problems are the improper adjustment of beam limiting devices and automatic exposure control. These are recorded not only in the test reports but also in official letters written to the competent leaders of the health institutions. As it always happens in the warranty period, these servicing or adjustments are free of charge for them. We mention that with our measuring instruments we could detect differences between specified and actual filtration or between displayed and actual X-ray tube current. Acceptance tests are always non-invasive.

We also mention that QA has been a daily practice in radiation therapy and nuclear medicine for a long time. A National Patient Dose Assessment Programme has also successfully run since 1989, with co-ordination of NRIRR.

\section{Status testing}

A status test means a full performance measurement equivalent to an acceptance test, although some simplifications are possible. (E.g. checking of documents and measurement of leakage radiation or tabletop attenuation can be omitted.) 
Accreditation of NRIRR - besides acceptance testing - contains also status testing. During 2006-2007 two further testing laboratories got accreditation for status testing from the Hungarian National Accreditation Body, and the number of accredited testing laboratories probably will grow further.

These laboratories are fully equipped with calibrated measuring instrumentation and work with highly qualified personnel. We hope that they will start the work in the near future.

As total replacement of the equipment park is likely needs more than 15 years, initializing QA programmes on existing equipment is a longer process.

We mention that constancy testing performed by the users (licensees) (or services) contains only very simple checks so they are not applying IEC/EN standards.

\section{Type testing according to safety standards}

It is also one of the accredited test methods of NRIRR. Such tests are performed rarely as a subcontractor activity, ordered by one of the notified certifying bodies. Practice of the last 6 years includes several X-ray generator testing and one experimental small-animal PET/CT (only CT part) testing (all are Hungarian products).

\section{Conclusions - future of testing according to IEC/EN standards}

Safety testing applying safety and essential performance standards will be based on new generation of these standards, performed either by the manufacturers or - as type testing - by certifying bodies or accredited testing laboratories.

As for application of the acceptance testing standards, the older standards are not applicable to the newest equipment so their revision would be needed.

It is not known yet, whether the standards (radiography/radioscopy, DSA, dental equipment) will be revised or only withdrawn. (Decision in the IEC is under preparation.) Namely, some countries have own independent QA regulation, while others use a European document, the so-called RP91 ("Criteria for acceptability of radiological (including radiotherapy) and nuclear medicine installations"), first edition of which was issued in 1997. A second edition is now under elaboration, with the aim of reaching the possible widest consensus, including also manufacturers. In case of lack of 
new international standards a new regulation may be based on this EU document, which probably will be issued in 2010 .

\section{Acknowledgements}

The authors express their thanks to Dr Norbert Bischof, secretary of IEC TC62 and SC62B, for the information highlighting activities of IEC.

\section{References}

[1] Council Directive 93/42/EEC of 14 June 1993 concerning Medical Devices, O.J. L 169, 1993, 1-51.

[2] Council Directive 97/43/Euratom of 30 June 1997 on Health Protection of Individuals Against the Dangers of Ionizing Radiation in Relation to Medical Exposure, and repealing Directive 84/466/Euratom, O.J. L 180, 1997, 22-27. 